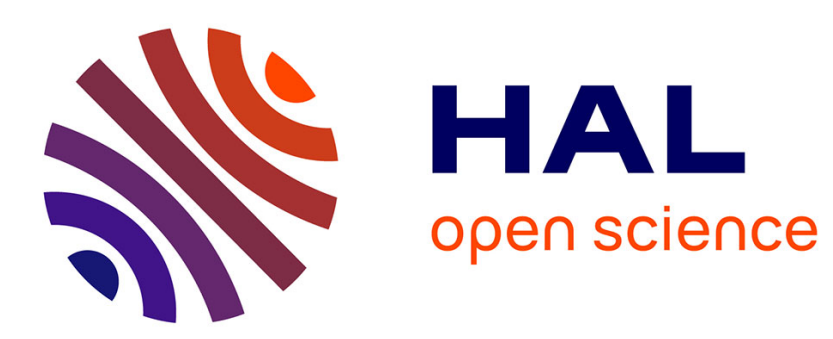

\title{
Calibration of material parameters of anisotropic yield criterion with conventional tests and biaxial test
} Shunying Zhang, Lionel Leotoing, Dominique Guines, Sandrine Thuillier

\section{To cite this version:}

Shunying Zhang, Lionel Leotoing, Dominique Guines, Sandrine Thuillier. Calibration of material parameters of anisotropic yield criterion with conventional tests and biaxial test. 16th annual ESAFORM Conference on Material Forming, Apr 2013, Aveiro, Portugal. pp.2111-2117, 10.4028/www.scientific.net/KEM.554-557.2111 . hal-00872583

\section{HAL Id: hal-00872583 https://hal.science/hal-00872583}

Submitted on 27 Mar 2014

HAL is a multi-disciplinary open access archive for the deposit and dissemination of scientific research documents, whether they are published or not. The documents may come from teaching and research institutions in France or abroad, or from public or private research centers.
L'archive ouverte pluridisciplinaire HAL, est destinée au dépôt et à la diffusion de documents scientifiques de niveau recherche, publiés ou non, émanant des établissements d'enseignement et de recherche français ou étrangers, des laboratoires publics ou privés. 


\title{
Calibration of material parameters of anisotropic yield criterion with conventional tests and biaxial test
}

\author{
ZHANG Shunying ${ }^{1, a}$, LEOTOING Lionel ${ }^{1, b}$, GUINES Dominique ${ }^{1, c}$, \\ THUILLIER Sandrine ${ }^{2, \mathrm{~d}}$ \\ ${ }^{1}$ LGCGM, INSA, UEB, 20 avenue des Buttes de Coësmes, 35708 Rennes Cedex France \\ 2LIMATB, Université de Bretagne-Sud, rue de Saint Maudé, BP 92116, 56321 Lorient Cedex \\ France \\ ashunying.zhang@insa-rennes.fr, \\ blionel.leotoing@insa-rennes.fr, \\ cominique.guines@insa-rennes.fr, \\ dsandrine.thuillier@univ-ubs.fr
}

Keywords: Plastic anisotropy, Yield criterion, Biaxial test, Material parameter identification

\begin{abstract}
.
Bron and Besson yield criterion has been used to investigate the plastic anisotropic behavior of an aluminum alloy AA5086. The parameters of this anisotropic yield model have been identified by two different methods: a classical one, considering several homogeneous conventional experiments and an exploratory one, with only biaxial test. In this paper, the parameter identification with conventional experiments has been carried out with uniaxial tensile tests and simple shear tests in different orientations to the rolling direction and with a hydraulic bulge test. For comparison's sake, Hill's 48 yield function has also been calibrated analytically from uniaxial tensile tests. Numerical simulation for the cross biaxial test has been carried out with the anisotropic parameters identified from the conventional tests. From this simulation, the principle strains along a specified path in the gauge area of the cruciform specimen have been evaluated. A good agreement is observed between experimental and numerical values of principal strains for a large range of strain paths.
\end{abstract}

\section{Introduction}

Sheet metal forming represents a class of important processes widely used in the manufacture industry. Sheet metals usually exhibit a plastic anisotropy due to previous processes like rolling and annealing. To optimize the numerical simulation of these forming processes, a precise description of the plastic behavior is required. Yield functions are frequently applied to describe the material behavior and to take into account the initial anisotropy and hardening for the subsequent evolution with plastic strain. Yield functions can contain a high number of parameters. The calibration of these parameters requires many mechanical tests with different loading modes. The classical approach is to identify the yield criterion parameters from initial yield stresses and anisotropy coefficients. Barlat and co-authors [1] calibrated the yield function Yld2004-18p with uniaxial tensile tests and hydraulic bulge test. To identify the parameters of BBC2002 yield function, Banabic et al [2] used uniaxial tensile test and cross biaxial test. The cruciform specimen is used to obtain the uniaxial flow stress in rolling direction and transverse direction. The biaxial stress is obtained by dividing the measured force by an effective area. The limit of this approach lies in the imprecision of the determination of the initial yield stress due to the difficulty to define the effective area. Another approach consists in a parameter identification over the temporal evolution of experimental data. Zang et al [3] considered a combination of stress level in uniaxial tension, simple shear test, Bauschinger test and bulge test to identify the Bron and Besson yield function [4]. 
In the present article, the plastic anisotropy of an AA5086 is characterized from conventional experiments: uniaxial tensile test, bulge test and simple shear test. From these conventional results, 2 yield functions have been identified: the well known Hill's 1948 yield function [5] and a more sophisticated one, the Bron and Besson yield function. Finally, a biaxial tensile test on a cruciform specimen is proposed. The identified Bron and Besson yield function is then introduced in the FE model of the biaxial tensile test. Comparison between experimental and numerical results of principal strains along a specified path is performed. It is shown that the cross-biaxial test involves a large range of strain paths.

\section{Mechanical behavior of AA5086 sheets of 2 mm thickness}

Assuming orthotropic symmetry, $(x, y, z)$ are respectively the rolling direction (RD), the transverse direction (TD) and the normal direction (ND). In the frame of a uniaxial tensile test, $\left(x^{\prime}, y^{\prime}, z^{\prime}\right)$ are respectively the elongation direction, the transverse direction and the normal direction.

\section{Hill's 1948 yield function.}

Hill's 1948 orthotropic yield function is written in the following form:

$$
\psi=F\left(\sigma_{y y}-\sigma_{z z}\right)^{2}+G\left(\sigma_{z z}-\sigma_{x x}\right)^{2}+H\left(\sigma_{x x}-\sigma_{y y}\right)^{2}+2 L \sigma_{y z}^{2}+2 M \sigma_{x z}^{2}+2 N \sigma_{x y}^{2}=\bar{\sigma}^{2}=Y_{0}^{2}
$$

where $\psi$ denotes the yield function, $\bar{\sigma}$ is the equivalent stress, $Y_{0}$ a reference yield stress of the material, $F, G, H, L, M$ and $N$ are material parameters. With the condition: $G+H=1$, and plane stress condition $\left(\sigma_{z z}=\sigma_{x z}=\sigma_{y z}=0\right)$, three independent anisotropic parameters have to be identified $(F, G$ and $N)$ :

$$
F=\frac{r_{0}}{r_{90}\left(r_{0}+1\right)}, G=\frac{1}{r_{0}+1} \text { and } N=\frac{\left(1+2 r_{45}\right)\left(r_{0}+r_{45}\right)}{2 r_{90}\left(1+r_{0}\right)}
$$

Hill's parameters can be calculated by three anisotropic coefficients $r_{\theta}\left(\theta=0,45^{\circ}, 90^{\circ}\right)$ defined by:

$$
r_{\theta}=\frac{\dot{\varepsilon}_{y^{\prime} y^{\prime}}}{\dot{\varepsilon}_{z^{\prime} z^{\prime}}}
$$

\section{Bron and Besson yield function.}

Bron and Besson proposed a 16 parameters yield function which is in the form:

$$
\psi=\sum_{k=1}^{2} \alpha^{k}\left(\bar{\sigma}^{k}\right)^{a}=\bar{\sigma}^{a}=Y_{0}^{a}
$$

The yield function $\psi$ consists in two convex functions. $\alpha^{k}$ are positive coefficients, the sum of which is equal to $1 . \bar{\sigma}^{k}$ are expressed in the form:

$$
\begin{aligned}
& \bar{\sigma}^{1}=\left(\frac{1}{2}\left(\left|S_{2}^{1}-S_{3}^{1}\right|^{b^{1}}+\left|S_{3}^{1}-S_{1}^{1}\right|^{b^{1}}+\left|S_{2}^{1}-S_{1}^{1}\right|^{b^{1}}\right)\right)^{1 / b^{1}} \\
& \bar{\sigma}^{2}=\left(\frac{3^{b^{2}}}{2^{b^{2}}+2}\left(\left|S_{1}^{2}\right|^{b^{2}}+\left|S_{2}^{2}\right|^{b^{2}}+\left|S_{3}^{2}\right|^{b^{2}}\right)\right)^{1 / b^{2}}
\end{aligned}
$$

where $a, b^{1}, b^{2}$ and $\alpha^{1}\left(\alpha^{2}=1-\alpha^{1}\right)$ are four isotropic parameters which define the shape of the yield surface. $S_{i}^{k}$ are the principal values of the transformed stress deviators $\mathrm{s}_{\mathrm{ij}}^{\prime \mathrm{k}}$, defined by:

$$
\mathrm{s}_{\mathrm{ij}}^{\prime{ }^{\mathrm{k}}}=L^{k} \sigma_{i j}
$$


with $L^{k}=\left(\begin{array}{cccccc}\frac{c_{2}^{k}+c_{3}^{k}}{3} & -\frac{c_{3}^{k}}{3} & -\frac{c_{2}^{k}}{3} & 0 & 0 & 0 \\ -\frac{c_{3}^{k}}{3} & \frac{c_{1}^{k}+c_{3}^{k}}{3} & -\frac{c_{1}^{k}}{3} & 0 & 0 & 0 \\ -\frac{c_{2}^{k}}{3} & -\frac{c_{1}^{k}}{3} & \frac{c_{1}^{k}+c_{2}^{k}}{3} & 0 & 0 & 0 \\ 0 & 0 & 0 & c_{4}^{k} & 0 & 0 \\ 0 & 0 & 0 & 0 & c_{5}^{k} & 0 \\ 0 & 0 & 0 & 0 & 0 & c_{6}^{k}\end{array}\right)$

where $c_{i}^{k}$ are 12 parameters which are related to the anisotropy of the material. There are a total of 16 parameters in Bron and Besson yield model. In plane stress condition, the parameter number reduces to 12 with $c_{5}^{k}=c_{6}^{k}=1$.

\section{Material data.}

In this work, the parameters of the Bron and Besson yield function described above have been calibrated by: three yield stresses $\left(\sigma_{0}, \sigma_{45}\right.$ and $\left.\sigma_{90}\right)$ and three anisotropic coefficients $\left(r_{0}, r_{45}\right.$ and $\left.r_{90}\right)$ obtained from the uniaxial tensile tests in different orientations; three simple shear stresses $\left(\tau_{0}\right.$, $\tau_{45}$ and $\left.\tau_{90}\right)$ from three simple shear tests in different orientations; an equi-biaxial yield stress $\left(\sigma_{b}\right)$ and a biaxial coefficient $\left(r_{b}\right)$ from biaxial tension (bulge test).

\section{Material parameter identification.}

In the plane stress condition, $\sigma_{x x}, \sigma_{y y}, \sigma_{x y}$ and $\sigma_{y x}$ are the only non-zero stress components. With the associated flow rule:

$$
\dot{\varepsilon}_{i j}=\dot{\lambda} \frac{\partial \psi}{\partial \sigma_{i j}}
$$

Strain increment can be written in the form of yield function gradient:

$$
\dot{\varepsilon}_{i j}=\dot{\lambda}\left(\begin{array}{ccc}
\frac{\partial \psi}{\partial \sigma_{x x}} & \frac{\partial \psi}{\partial \sigma_{x y}} & 0 \\
\frac{\partial \psi}{\partial \sigma_{y x}} & \frac{\partial \psi}{\partial \sigma_{y y}} & 0 \\
0 & 0 & -\left(\frac{\partial \psi}{\partial \sigma_{x x}}+\frac{\partial \psi}{\partial \sigma_{y y}}\right)
\end{array}\right)
$$

Suppose that the uniaxial tensile test is performed along a direction defined by an orientation angle $\theta$ from the rolling direction. Then the anisotropic coefficient $r_{\theta}$ which is associated with orientation angle $\theta$ can be calculated by:

$$
r_{\theta}=\frac{\dot{\varepsilon}_{y^{\prime} y^{\prime}}}{\dot{\varepsilon}_{z^{\prime} z^{\prime}}}=\frac{\sin ^{2} \theta\left(\partial \psi / \partial \sigma_{x x}\right)-\sin 2 \theta\left(\partial \psi / \partial \sigma_{x y}\right)+\cos ^{2} \theta\left(\partial \psi / \partial \sigma_{y y}\right)}{\left(\partial \psi / \partial \sigma_{x x}\right)+\left(\partial \psi / \partial \sigma_{y y}\right)}
$$

The biaxial coefficient $r_{b}$ is calculated in the form:

$$
r_{b}=\frac{\dot{\varepsilon}_{y y}}{\dot{\varepsilon}_{z z}}=\frac{\partial \psi / \partial \sigma_{y y}}{\partial \psi / \partial \sigma_{x x}}
$$


The identification process can be carried out by minimizing the following cost function:

$$
\begin{gathered}
\delta\left(a, b^{i}, \alpha_{1}, c_{i}^{k}\right)=\sum_{j=1}^{3}\left(\frac{\bar{\sigma}_{\theta_{j}}-Y_{0}{ }^{2}}{Y_{0}}\right)+\left(\frac{\bar{\sigma}_{b}-Y_{0}}{Y_{0}}\right)^{2}+\sum_{j=1}^{3}\left(\frac{r_{\theta_{j}}-r_{\theta_{j}}^{\exp }}{r_{\theta_{j}}^{\exp }}\right) \\
+\left(\frac{r_{b}-r_{b}^{\exp }}{r_{b}^{\exp }}\right)^{2}+\frac{1}{3} \sum_{j=1}^{3}\left(\frac{\bar{\tau}_{\theta}-Y_{0}}{Y_{0}}\right)^{2}
\end{gathered}
$$

where $Y_{0}$ is the reference yield stress determined by the flow stress along rolling direction; $r_{\theta_{j}}^{\exp }$ and $r_{b}^{\exp }$ are respectively measured anisotropic coefficients and biaxial coefficient; $r_{\theta_{j}}$ (Eq. 9) and $r_{b}$ (Eq. 10) are predicted anisotropic coefficients and biaxial coefficients; $\bar{\sigma}_{\theta_{j}}, \bar{\sigma}_{b}$ and $\bar{\tau}_{\theta}$ are equivalent stresses obtained by the definition of yield function (Eq. 4) and expressed in terms of the measured yield stress $\left(\sigma_{\theta_{j}}\right)$, biaxial stress $\left(\sigma_{b}\right)$ and shear stress $\left(\tau_{\theta}\right)$. A weight coefficient is given to the shear stress since the uncertainty of the determination of the initial shear stress.

The major task lies in the optimization of the anisotropic parameters to minimize the cost function. The algorithm Broyden-Fletcher-Goldfarb-Shanno (BFGS) is preferred here. BFGS is an approximate Newton's method, which is a hill-climbing optimization.

\section{Application for AA5086.}

Experimental material data for AA5086 is given in Table 1. The initial yield stress for uniaxial tensile test is determined at the onset of a non-linearity on the equivalent stress versus equivalent strain curve. For simple shear test and hydraulic bulge test, the initial yield point is determined by the offset equivalent plastic strain $0.2 \%$. The anisotropic coefficients $\left(r_{0}, r_{45}, r_{90}\right)$ are defined as the average value in an equivalent plastic strain range from $5 \%$ to $15 \%$.

Table 1. Material data

\begin{tabular}{|c|c|c|c|c|c|c|c|c|c|c|c|}
\hline $\begin{array}{c}Y_{0} \\
{[\mathrm{MPa}]}\end{array}$ & $\begin{array}{c}\sigma_{0} \\
{[\mathrm{MPa}]}\end{array}$ & $\begin{array}{c}\sigma_{45} \\
{[\mathrm{MPa}]}\end{array}$ & $\begin{array}{c}\sigma_{90} \\
{[\mathrm{MPa}]}\end{array}$ & $\begin{array}{c}\sigma_{b} \\
{[\mathrm{MPa}]}\end{array}$ & $\begin{array}{c}\tau_{0} \\
{[\mathrm{MPa}]}\end{array}$ & $\begin{array}{c}\tau_{45} \\
{[\mathrm{MPa}]}\end{array}$ & $\begin{array}{c}\tau_{90} \\
{[\mathrm{MPa}]}\end{array}$ & $r_{0}$ & $r_{45}$ & $r_{90}$ & $r_{b}$ \\
\hline 135 & 135 & 131 & 131 & 122 & 59.7 & 63.3 & 61 & 0.42 & 0.59 & 0.45 & 1.03 \\
\hline
\end{tabular}

The 12 parameters of Bron and Besson yield function calculated from the experimental data presented above are given in Table 2.

Table 2. Anisotropic parameters of Bron and Besson yield function

\begin{tabular}{|c|c|c|c|c|c|c|c|c|c|c|c|}
\hline \multicolumn{10}{|c|}{ Bron and Besson yield function } \\
\hline$\alpha_{1}$ & $a$ & $b^{1}$ & $b^{2}$ & $c_{1}^{1}$ & $c_{2}^{1}$ & $c_{3}^{1}$ & $c_{4}^{1}$ & $c_{1}^{2}$ & $c_{2}^{2}$ & $c_{3}^{2}$ & $c_{4}^{2}$ \\
\hline 0.234 & 13.174 & 53.026 & 39.832 & -1.120 & -1.112 & 2.138 & -1.082 & 1.147 & 1.056 & 0.874 & -0.963 \\
\hline
\end{tabular}

As a comparison, Hill's 48 yield criterion has been calibrated by the three $\left(r_{0}, r_{45}, r_{90}\right)$ values :

Table 3. Anisotropic parameters of Hill's 1948 yield function

\begin{tabular}{|c|c|c|c|}
\hline \multicolumn{4}{|c|}{ Hill's 1948 yield function } \\
\hline $\mathrm{F}$ & $\mathrm{G}$ & $\mathrm{H}$ & $\mathrm{N}$ \\
\hline 0.657 & 0.704 & 0.296 & 1.484 \\
\hline
\end{tabular}

Figs. 1 to 4 show the results for both Bron and Besson and Hill's 1948 yield functions. Both functions well predict the anisotropic coefficients. For the uniaxial yield stresses, Bron and Besson yield function describes them well, while Hill's 1948 yield model has not the ability to adjust its 
variation. For the shear stresses, comparing with experimental values, Bron and Besson yield function shows a little overestimation but has a good description of their variation. The associated yield surfaces for the two yield functions present significant differences.

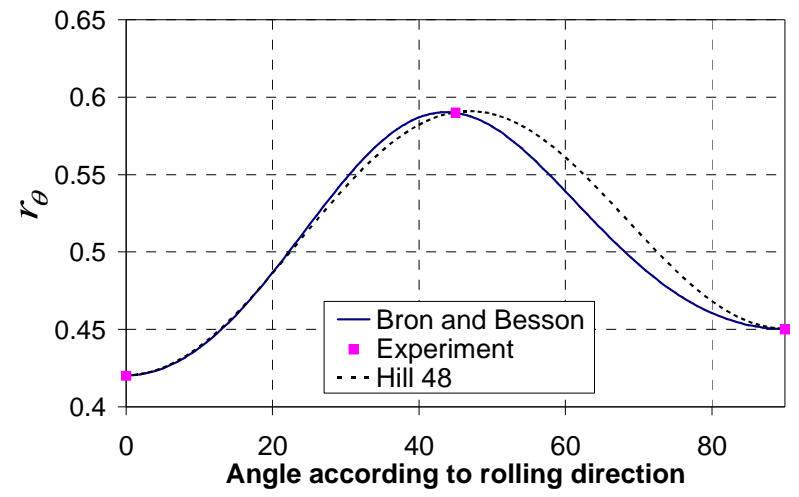

Fig. 1 Experimental and predicted $r$ values

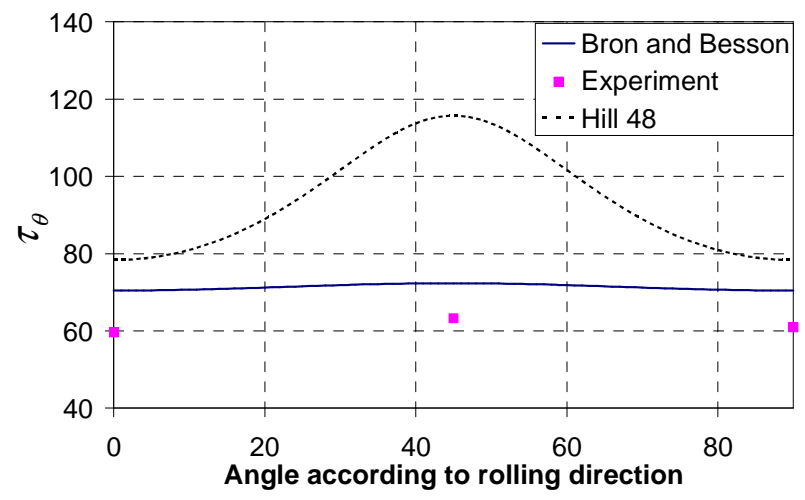

Fig. 3 Experimental and predicted shear stress

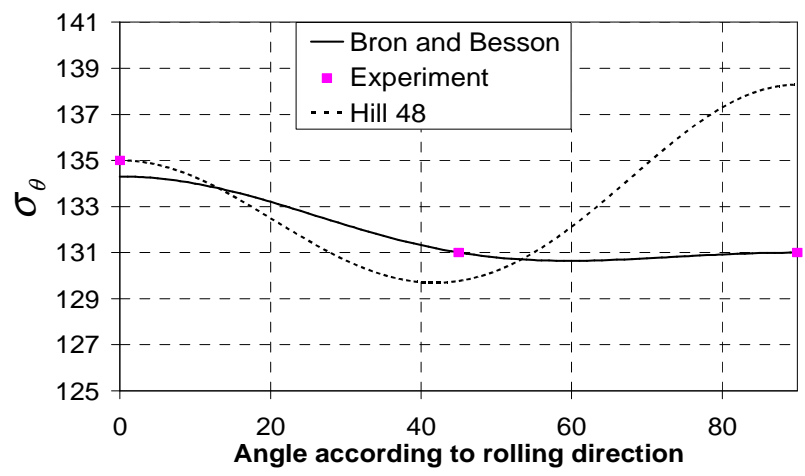

Fig. 2 Experimental and predicted uniaxial stress

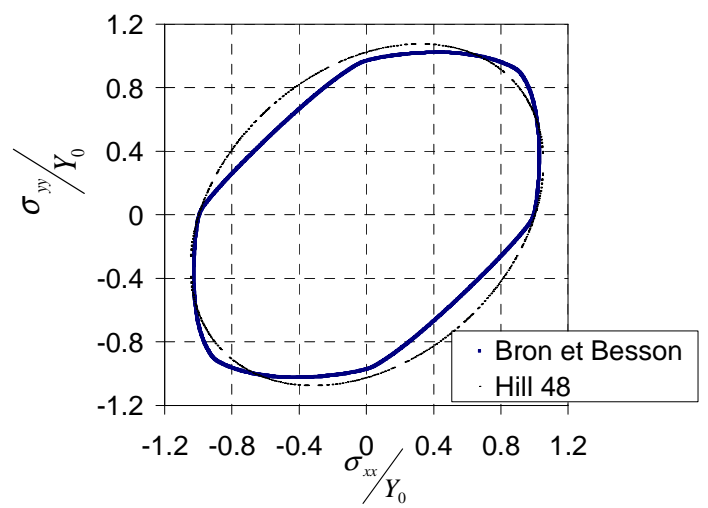

Fig. 4 Predicted yield surface contours

\section{Biaxial tensile test}

To simplify both the design of the experimental database and the calibration of anisotropic parameters of the yield function, a second method based on a cross biaxial tensile test is currently investigated. This test seems particularly interesting since different strain paths can be obtained simultaneously with a unique specimen. Up to now, few works have been focused on the parameter identification of yield function from the biaxial tensile test. Green et al [6] have performed cross biaxial test with seven different proportional paths to identify the parameters of the yield functions which couldn't be identified by uniaxial tensile test. Teaca et al [7] proposed to identify the FMM yield function [8] in combining results of uniaxial tensile tests and cross biaxial test. Only two parameters of the yield model were calibrated from a strain analysis of the central part of the cruciform specimen.

In this paper, the potential of the biaxial tensile test on a cruciform specimen is analyzed. A cruciform specimen shape has been designed and is shown in Fig. 5. Experiments on a servohydraulic testing machine have been performed with a constant velocity ratio $v_{x} / v_{y}=1 \mathrm{~mm} / \mathrm{s}$ imposed on the four arms of the cruciform specimen. The central zone of the specimen is filmed by a camera and a digital image correlation (DIC) technic is used to compute the in-plane strains. 


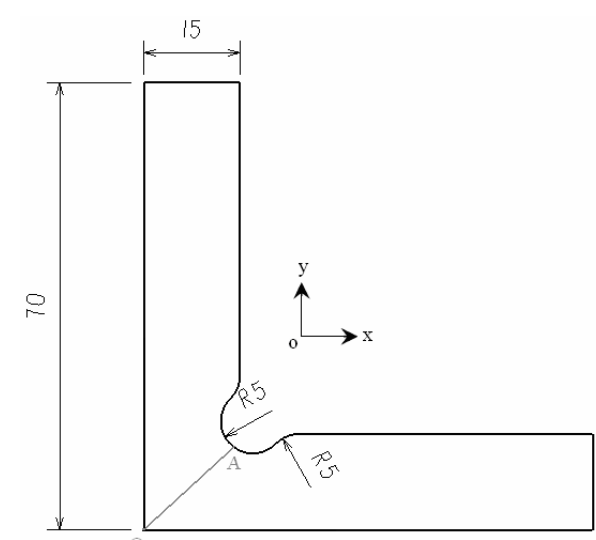

Fig. 5 Geometry of quarter cruciform specimen

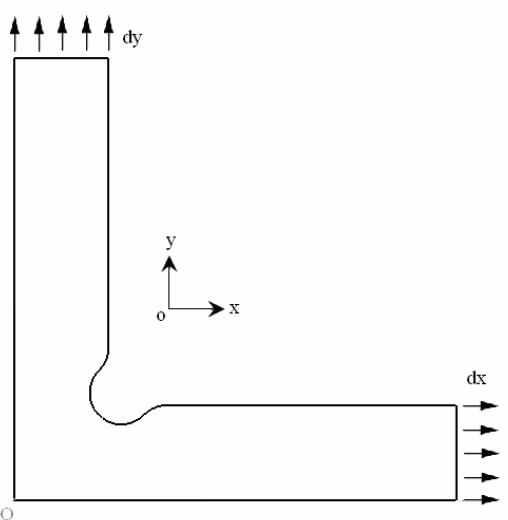

Fig. 6 FE boundary conditions

Finite element simulations of the biaxial test have been carried out with the commercial software ABAQUS. The anisotropic behavior of the material is modeled by Bron and Besson yield function implemented through the user subroutine UMAT with the parameters calculated above (Table 2). Due to the symmetry of the cruciform specimen, only a quarter of the specimen is modeled. Displacements $d_{x}=d_{y}=4 \mathrm{~mm}$ are imposed on two arms of the cruciform specimen during the simulation process. As presented in Fig. 7, the principal strains at the nodes along the diagonal path OA (Fig. 5) in the gauge area of the specimen have been obtained and compared with the experimental values. The predicted principal strains are quite close to the experimental ones.

Fig. 8 presents the experimental and predicted ratio of the principal strains along the path OA. As can be seen, the gauge area of the cruciform specimen contains a large range of strain path: from equi-biaxial to uniaxial strain path, which can be particularly interesting for the parameter identification instead of the above tests used in the conventional approach. The parameter identification process with only cross biaxial tensile test will be carried out in next research works by minimizing the experimental and FE simulated principal strains along different paths.

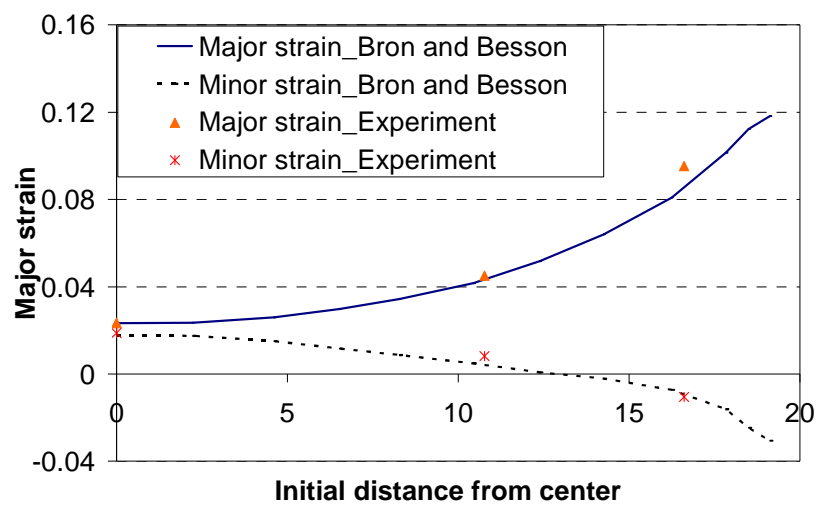

Fig. 7 Experimental and predicted principal strains along a diagonal path

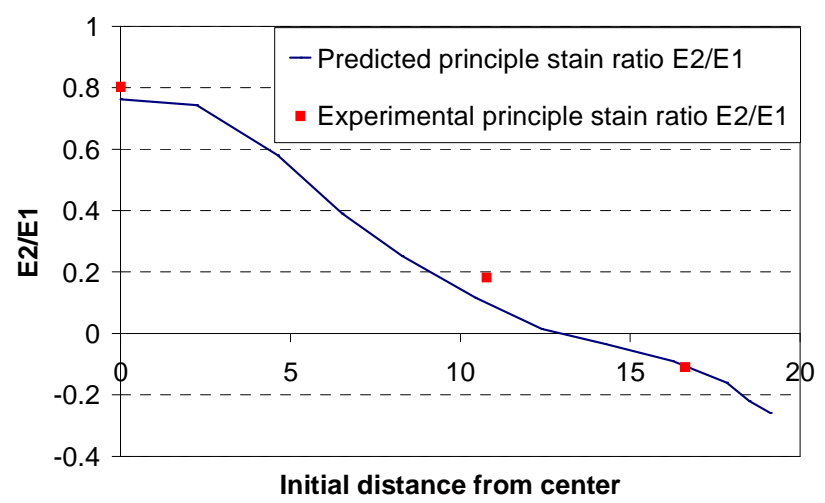

Fig. 8 Experimental and predicted principal strain ratio along a diagonal path

\section{Conclusion}

This research work focuses on the anisotropic parameter calibration of Bron and Besson yield function used to investigate the plastic anisotropic behavior of AA5086 sheet. The parameters of the yield function have been calculated from a classical approach based on three uniaxial tensile tests, three simple shear tests and a hydraulic bulge test. Numerical simulation of the cross biaxial test has been performed with the parameters obtained by this classical approach. The predicted principal strains along a specified path in the gauge area of the cruciform specimen are in good agreement 
with experimental ones. Based on this cross biaxial tensile test, a new identification procedure of the anisotropic parameters of Bron and Besson yield function will be proposed in future works.

\section{References}

[1] F. Barlat, H. Aretz, J. W. Yoon, M. E. Karabin, J. C. Brem, and R. E. Dick, Linear transfomation-based anisotropic yield functions, International Journal of Plasticity. 21 (2005) 1009-1039.

[2] D. Banabic, H. Aretz, D. S. Comsa, and L. Paraianu, An improved analytical description of orthotropy in metallic sheets, International Journal of Plasticity. 21 (2005) 493-512.

[3] S. L. Zang, S. Thuillier, A. Le Port, and P. Y. Manach, Prediction of anisotropy and hardening for metallic sheets in tension, simple shear and biaxial tension, International Journal of Mechanical Sciences. 53 (2011) 338-347.

[4] F. Bron and J. Besson, A yield function for anisotropic materials Application to aluminum alloys, International Journal of Plasticity. 20 (2004) 937-963.

[5] R. Hill, A Theory of the Yielding and Plastic Flow of Anisotropic Metals, Proceedings of the Royal Society of London. Series A, Mathematical and Physical Sciences. 193 (1948) 281-297.

[6] D. E. Green, K. W. Neale, S. R. MacEwen, A. Makinde, and R. Perrin, Experimental investigation of the biaxial behaviour of an aluminum sheet, International Journal of Plasticity. 20 (2004) 1677-1706.

[7] M. Teaca, I. Charpentier, M. Martiny, and G. Ferron, Identification of sheet metal plastic anisotropy using heterogeneous biaxial tensile tests, International Journal of Mechanical Sciences. 52 (2010) 572-580.

[8] G. Ferron, R. Makkouk, and J. Morreale, A parametric description of orthotropic plasticity in metal sheets, International Journal of Plasticity. 10 (1994) 431-449. 